\title{
Extra-tropical cyclones in the present and future climate: a review
}

\author{
U. Ulbrich • G. C. Leckebusch • J. G. Pinto
}

Received: 5 March 2008 / Accepted: 1 June 2008 / Published online: 17 January 2009

(C) The Author(s) 2009. This article is published with open access at Springerlink.com

\begin{abstract}
Based on the availability of hemispheric gridded data sets from observations, analysis and global climate models, objective cyclone identification methods were developed and applied to these data sets. Due to the large amount of investigation methods combined with the variety of different datasets, a multitude of results exist, not only for the recent climate period but also for the next century, assuming anthropogenic changed conditions. Different thresholds, different physical quantities, and considerations of different atmospheric vertical levels add to a picture that is difficult to combine into a common view of cyclones, their variability and trends, in the real world and in GCM studies. Thus, this paper will give a comprehensive review of the actual knowledge on climatologies of mid-latitude cyclones for the Northern and Southern Hemisphere for the present climate and for its possible changes under anthropogenic climate conditions.
\end{abstract}

\section{Introduction}

Extra-tropical cyclones are dominant feature of the midlatitudes, as their passage is associated with strong winds,

\section{U. Ulbrich $(\bowtie) \cdot$ G. C. Leckebusch}

Freie Universität Berlin, Institute for Meteorology,

Carl-Heinrich-Becker-Weg 6-10,

12165 Berlin, Germany

e-mail: ulbrich@met.fu-berlin.de

G. C. Leckebusch

e-mail: gcl@met.fu-berlin.de

\section{J. G. Pinto}

Institute for Geophysics and Meteorology, University of Cologne, Kerpener Str. 13,

50923 Köln, Germany

e-mail: jpinto@meteo.uni-koeln.de precipitation, and temperature changes. Thus, cyclone activity represents an important measure of the state of the atmosphere. Information on the characteristics and paths of cyclones are important both in terms of understanding variations of local weather and for a characterization of climate. Such an approach was recently used for the assessment of (ensemble) forecasts and estimates of predictability (Froude et al. 2007a, 2007b). The current paper reviews the actual knowledge on the broader scale cyclone occurrence, including its identification and tracking from global data sets with "state-of-the-art" methods. It will not analyze and review the internal dynamical structure of cyclone systems and any classification based on it (e.g., Deveson et al. 2002; Gray and Dacre 2006).

Initial approaches of cyclone detection and tracking were based on manual analysis of synoptic weather charts (e.g., van Bebber 1891). Such analysis is very time-consuming, and could hence only be applied to a limited number of maps. Moreover, there is an inherent subjectivity to the results, as cyclone intensities and locations in weather maps were often estimated from scarce data, and thus were partly based on the individual meteorologist's experience (Haak and Ulbrich 1996). With the increase of computer capacity in recent decades, new automatic and semi-automatic methods were developed to objectively identify cyclones in digital maps. For the Southern Hemisphere (SH), an objective cyclone identification algorithm running on digitalized data was firstly introduced by Rice (1982). More sophisticated schemes were developed and applied in the following decades. Consequently, a large number of research papers have been brought out in recent years on cyclone activity, both based on reanalysis data or on Global Circulation Model (GCM) data. Comparing the estimations of spatial distributions and intensities of cyclone activity presented in these papers, a spread of results is found, 
equally originating from the differences between the underlying data (i.e., the particular reanalysis dataset or GCM, or the particular time period considered) and from the use of different measures of cyclone activity. It is worth mentioning that the different measures employed by the different authors mirror the variety of different physical aspects of cyclone activity. Our aim is to provide a succinct overview of the approaches for cyclone identification and for the quantification of cyclone activity used in published work. We will also reference results on observed trends, on the GCMs' representation of cyclone climatologies, and on climate change effects, aiming at a resume of the consensual results, and an analysis of the possible reasons for the non-consensual results.

\section{Methodologies}

The main focuses of this section are the schemes for identification and tracking of cyclones. In recent years, many numerical algorithms have been developed in order to objectively identify cyclones from digital data (e.g., Lambert 1988; Le Treut and Kalnay 1990; Murray and Simmonds 1991; König et al. 1993; Hodges 1994, 1995; Serreze 1995; Haak and Ulbrich 1996; Blender et al. 1997; Sinclair 1994, 1995, 1997; Simmonds et al. 1999; Lionello et al. 2002; and Wernli and Schwierz 2006). While all schemes identify cyclone positions (Sect. 2.1), some of them involve a second tracking step in which the individual cores are connected to paths (Sect. 2.2). The different procedures vary greatly with respect to computational details and the degree of sophistication involved. An additional source of differences stems from the possibilities for quantifying cyclone strength and activity (Sect. 2.3). The bandpass filtering technique (sometimes called "Eulerian approach") is presented in Sect. 2.4.

\subsection{Cyclone identification}

In a manual identification based on operational weather maps, cyclone positions are usually identified as pressure minima in MSLP, or as minima in 1,000-hPa geopotential heights. Schinke (1993, for the North Atlantic region) and Chen and Zhang (1996, for Asia and the northwest Pacific) search for the corresponding closed MSLP isolines on maps. This manual approach is approximated by the automatic identification schemes in different ways. Wernli and Schwierz (2006) propose an automated cyclone identification scheme that identifies cyclones using the closed MSLP contour lines around local minima. In other schemes, the identification of the positions and core depths is based on a comparison of neighboring grid points in the basic data (Lambert 1988; Graham and Diaz 2001; Maheras et al. 2001; Lionello et al. 2002; Fyfe 2003). In some approaches, a complex interpolation of the input data is performed, followed by a subsequent iterative search for minima (e.g., Murray and Simmmonds 1991; Haak and Ulbrich 1996; Jung et al. 2006). Benestad and Chen (2006) recently developed a calculus-based cyclone identification based on an interpolation using truncated Fourier series.

A number of problems can affect the identification process described. Schemes operating on MSLP may produce unreliable results over high ground due to effects of vertical extrapolation and to differences in the representation of orography in the GCM and reanalysis datasets. Thus, authors often ignore systems identified in these regions (e.g., Murray and Simmmonds 1991; Wang et al. 2006a). In some regions, low pressure systems have characteristics different from the usual mid-latitude cyclones, such as monsoon depressions and heat lows (e.g., Chen and Zang 1996). Such lows can be partly discriminated by the application of cyclone tracking schemes (see Sect. 2.2) applying a set of empirical thresholds associated with cyclone tracking, e.g., minimum duration, minimum displacement, and minimum intensity (e.g., Serreze et al. 1997; Blender et al. 1997; Trigo et al. 1999; Pinto et al. 2005). Considering cyclones as anomalies superposed to a mean pressure field, some authors filter the data previously to the identification in order to remove any influence from the background flow (e.g., Hoskins and Hodges 2002). Cyclone identification is also applied to highresolution regional model data: for example, Lionello et al. (2008) apply a scheme originally used for GCM data (Lionello et al. 2002), while Musculus and Jacob (2005) make use of a scheme originally designed for the identification of watersheds in their search for grid-points belonging to individual Mediterranean cyclones.

Alternatively to the consideration of MSLP minima, a number of schemes identify maxima in low-level vorticity (e.g., $850 \mathrm{hPa}$, Hodges 1994). The use of this quantity implies an extension to the definition of cyclones, so that not only features with closed isobars are considered. Hodges et al. (2003) mention that vorticity is more focused on the high-frequency end of synoptic range, while SLP is better at capturing the low-frequency margin. A problem in using vorticity as the only parameter is the larger number of small-scale maxima (compared to MSLP minima), which makes the procedure much more dependent on the spatial resolution of the data. A combination of vorticity and pressure was used by König et al. (1993). Murray and Simmonds (1991), Serreze (1995) and Wang et al. (2006a) considered vorticity implicitly (via Laplacian of MSLP) but associate the cyclone position to the pressure minimum.

The number and depth of identified systems by the automatic schemes is generally dependent on the resolution of the original data (e.g., Blender and Schubert 2000; Zolina and Gulev 2002; Pinto et al. 2005). Higher- 
resolution data result in more systems, deeper cores, and longer tracks (see Sect. 2.2). Thus, local smoothing as a pre-processing step before the actual identification (e.g., Sinclair 1997) can have a major influence on the results. Also note that "resolution" not only refers to the grid of the dataset itself but also to that of the model producing the data, as dynamics and parameterizations in a model are affected by its spatial resolution (see also Sect. 3.2). Comparability of results based on models (and reanalysis) with different resolution can only partly be obtained by reducing the resolution in the spectral domain (Pinto et al. 2005), but the dynamical differences remain.

\subsection{Cyclone tracking}

An evaluation of cyclone tracks based on the prior identification step provides additional information about individual cyclones and about their climatology. Different phases of their life cycle can be identified, and statistics of cyclone life cycle characteristics (deepening rates, central pressure, velocities, life time) can be investigated when the tracks are known. On the basis of identified cyclone tracks, particularly interesting developments can be identified and investigated, for example the genesis of explosive cyclone developments (Lim and Simmonds 2002; Leslie et al. 2005). Tracking can be a basis for the classification of cyclones in terms of their development in size (Simmonds 2000; Rudeva and Gulev 2007), physical characteristics (e.g., Blender et al. 1997; Gaffney et al. 2007) or in terms of their impacts (e.g., Ulbrich et al. 2003). In addition, a removal of spurious or very short lived systems in cyclone identification schemes can be based on the subsequent tracking step, imposing minimum lifetime ( $24 \mathrm{~h}$ is a frequent threshold, or $12 \mathrm{~h}$ in Wang et al. 2006a), and minimum intensity criteria (e.g., Blender et al. 1997), and restricting evaluations of cyclone activity to systems which can be assigned to a track.

The tracking schemes employed are generally based on a nearest-neighbor search, partly taking into account an expected movement of a cyclone according to a consideration of flow dynamics and of previous motion of the system (e.g., Murray and Simmonds 1991; Simmonds et al. 1999; Lionello et al. 2002). Raible (2007), for example, identifies cyclone cores as $1,000-\mathrm{hPa}$ geopotential height minima and applies a next-neighbor search within $1,000 \mathrm{~km}$ based on twice daily data. The results of tracking, like those of identification, partly depend on the specific tuning of the schemes: Raible et al. (2008) recently compared the performance of three tracking schemes based on reanalysis data. While finding a good general correspondence between the tracks produced, they also note large differences in track length. Differences are larger in summer than in winter, suggesting that some schemes are more sensible to the generally weaker lows, which are more dominant in summer.
Greeves et al. (2007) demonstrate the effect of tracking relative vorticity at $850 \mathrm{hPa}$ instead of MSLP, applying the method of Hoskins and Hodges (2002) on ERA40 data. For the Pacific, the horizontal structures of the feature densities found from both quantities are largely similar, but the absolute numbers are much $(\sim 20-50 \%)$ lower with MSLP, even though both fields have been truncated spectrally to a T42 resolution. In the Pacific, the vorticity tracking also produces a maximum in the western North Pacific, which is not pronounced using MSLP tracking (Greeves et al. 2007, their Fig. 1a,b). Note that a tracking of systems can also be performed on atmospheric variables other than MSLP, geopotential height or low level vorticity (Hoskins and Hodges 2002).

\subsection{Quantification of cyclone intensity and activity}

Following the approaches based on an inspection of weather maps, many authors use cyclone core pressure in MSLP or relative minima $1,000-\mathrm{hPa}$ geopotential height fields as a measure of a low's intensity. However, to consider a cyclone as deviation from a regionally mean state (which is variable in time), may be seen as a drawback of such measures, as the obtained values are strongly influenced by the background flow (e.g., Hoskins and Hodges 2002). Alternative measures for cyclone intensity are thus preferred in several studies. Blender et al. (1997) and Raible et al. (2007), for example, use the mean gradient between the cyclone core and a radius of $1,000 \mathrm{~km}$ as a measure of cyclone intensity, while Murray and Simmonds' (1991) algorithm considers the Laplacian of MSLP computed with a certain radius around the cyclone centre. Wang et al. (2006a) quantify seasonal cyclone activity by summing up the local Laplacian of pressure of all cyclones at a grid point.

A basic approach for computing cyclone frequencies is counting their number of occurrence (from the identification scheme) or positions (from tracks) in grid squares (either simply on a fixed latitude-longitude grid, or referring to a fixed area size). Alternatively, cyclone activity can be quantified in terms of cyclone track density, i.e., the number of tracks crossing (within a certain radius) of a certain grid cell over a period of time. While the cyclone track densities are primarily influenced by fast moving cyclones, cyclone count statistics are primarily influenced by slow moving systems (cf. e.g., Pinto et al. 2005). However, it is obvious that the climatological patterns will deviate from each other. The different indicators and parameters represent different aspects of cyclone activity, justifying their consideration. It is possible to combine several different aspects of cyclone climatologies (e.g., cyclone intensity, frequency, and duration) into one measure (Zhang et al. 2004), but it is not clear if this gives better insight or overview than considering them individually. Finally, we would like to highlight the 
NCEP track density winter (ONDJFM, 195810-200703)
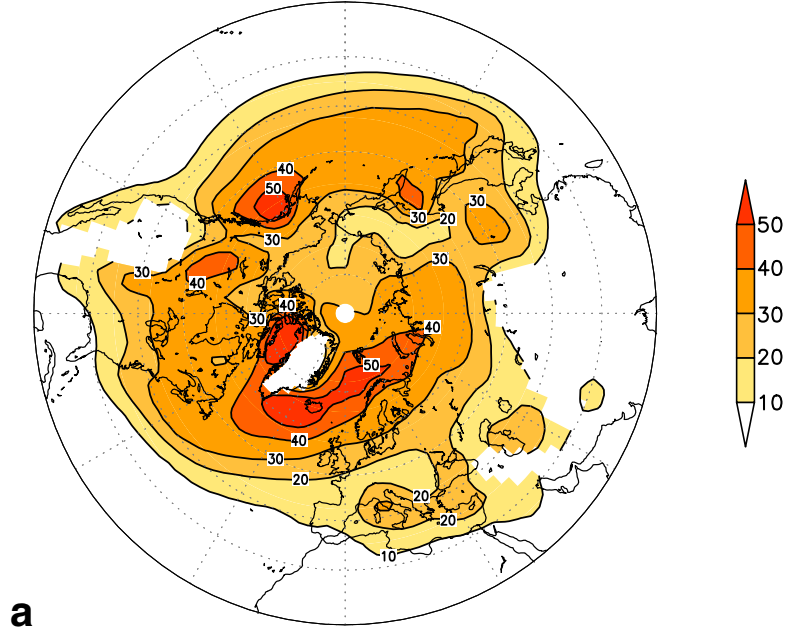

NCEP track density winter (AMJJAS, 195804-200609)
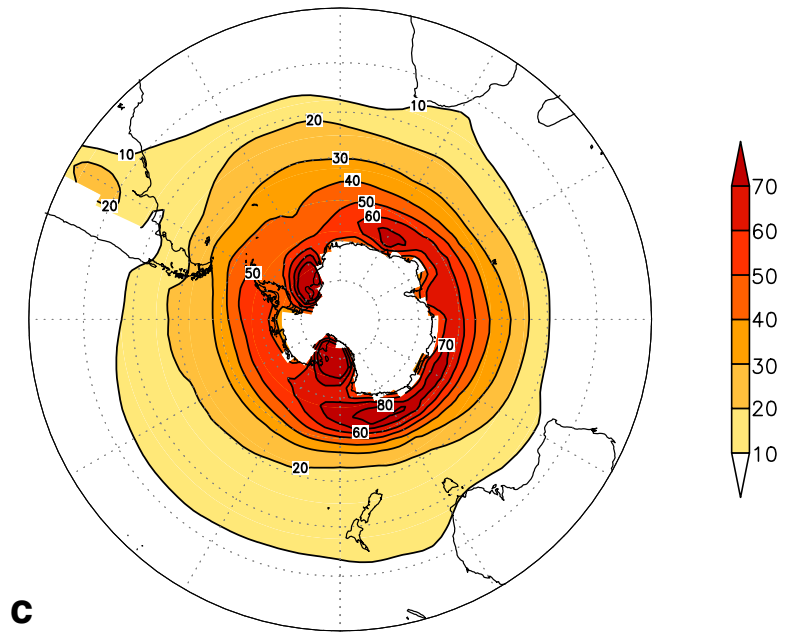

Fig. 1 a NH: NCEP-NCAR reanalysis track density, winter (ONDJFM) 1958/59-2006/07, all systems [cyclone days/winter], systems identified at grid points with surface heights above $1,500 \mathrm{~m}$ a.s.l. are removed. A $10^{\circ}$ longitude and $30^{\circ}$ latitude grid is included for easier reference. Figure adapted from Pinto et al. 2005, their Fig. 6a. b NH: NCEP-NCAR reanalysis track density, winter (ONDJFM) 1958/59-2006/07, 5\% strongest systems with respect to the Laplacian of MSLP [cyclone days/winter], systems identified at

systematic differences arising from a consideration of different vertical levels in the atmosphere. Lim and Simmonds (2007) studied the vertical characteristics of SH cyclones, finding more numerous, more intense, smaller, deeper, and slower systems at sea level than at upper levels.

\subsection{Quantification of variability without identification of individual systems}

A simple approach for the quantification of synoptic wave activity is based on the variability of mean sea level
NCEP track density (ONDJFM, 195810-200703), strongest 5\%

b

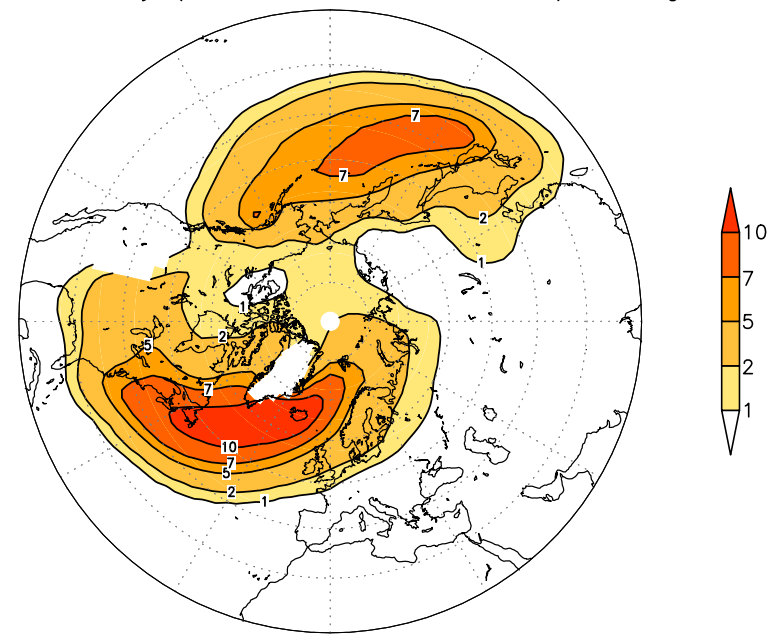

NCEP track density (AMJJAS, 195804-200709), strongest 5\%

d

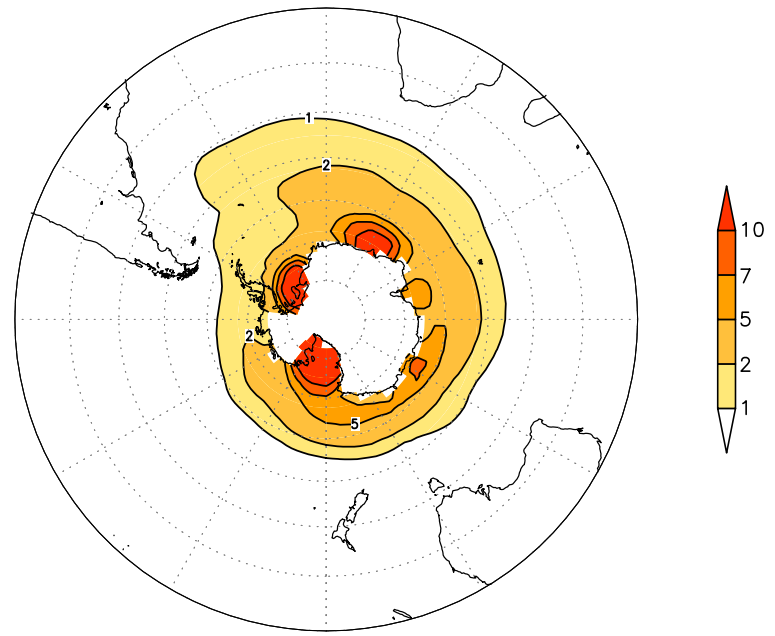

grid points with surface heights above $1,500 \mathrm{~m}$ a.s.l. are removed. c SH: NCEP-NCAR reanalysis track density, winter (AMJJAS) 19582006, all systems [cyclone days/winter], systems identified at grid points with surface heights above $1,000 \mathrm{~m}$ a.s.l. are removed. d SH: NCEP-NCAR reanalysis track density, winter (AMJJAS) 1958-2006, $5 \%$ strongest systems with respect to the Laplacian of MSLP [cyclone days/winter], systems identified at grid points with surface heights above $1,000 \mathrm{~m}$ a.s.l. are removed

pressure (MSLP) or geopotential height fields in the synoptic (about 2-6 days) time range (Wallace and Gutzler 1981; Blackmon et al. 1984a, 1984b; Wallace et al. 1988; Christoph et al. 1995). The standard deviation of this quantity, frequently entitled "storm track", gives a gross representation of the combined intensities and frequencies of low-pressure and high-pressure systems. It is robust against step-like non-climatic shifts in the data, similar to the recent approach of Wang et al. (2006b) who used MSLP deepening rates at stations in order to avoid uncertainties due to inhomogeneities in their station data. The storm 
track is partly influenced by the variability of the steering flow (Burkhardt and James 2006) due to Doppler effects. Aspects of synoptic variability are also found in neighboring frequency bands such as ultrahigh-frequency variability (0.5-2 days) and slow synoptic processes (6-12 days), each associated with climatological patterns usually not collocated with those for the synoptic band (Ayrault et al. 1995; Gulev et al. 2002).

\section{Climatologies from reanalysis data sets}

\subsection{General characteristics}

Applying the cyclone schemes to reanalysis datasets representing a specific observational time period, it is expected that the different methods produce very similar climatological distributions, e.g., indicating areas of more intense and of weaker cyclone activity. Basic climatological features are, indeed, common to the different approaches. We present NCEP-NCAR reanalysis cyclone track densities calculated with the updated Murray and Simmonds algorithm (Murray and Simmonds 1991; Pinto et al. 2005). Areas of high elevation are blanked out in the following figures as cyclone identification and tracking based on MSLP can be unreliable due to a potentially large effect of extrapolation below ground (see Sect. 2.1).

In the Northern Hemisphere (NH; Fig. 1a), the main activity areas are over the North Atlantic (NA) and over the North Pacific (NP). Winter intensities are found to be correlated with each other (Mak and Deng 2007). Secondary maxima are sometimes visible over the Asian continent and over the Mediterranean region. Cyclones are fewer (and weaker) during northern summer (not shown). If only strong cyclones are recognized (defined by the 5\% largest values of the Laplacian of pressure) the (cyclone track) frequencies are concentrated on the northern oceanic basins affecting North America and northwestern Europe, respectively (Fig. 1b). Included here are extreme winter storms that can produce large damages over Europe (cf. e.g., Hanson et al. 2004; Leckebusch et al. 2007; Pinto et al. 2007b). The regions of maximum deepening of winter cyclones and of highest cyclone velocity are found over the western ocean margin, while the cyclogenesis and cyclolysis regions are dominantly associated with the margins of high orography (Rocky Mountains, Greenland, Alps, Tibet, Japan) (e.g., Hoskins and Hodges 2002; Pinto et al. 2005; Bengtsson et al. 2006).

Most of the SH transient activity is organized between $30^{\circ}$ and $65^{\circ} \mathrm{S}$, including the storm and cyclone track region: the highest cyclone track densities are found south of $60^{\circ} \mathrm{S}$ and especially at the coastlines of East Antarctica with decreasing numbers to the north and south (Fig. 1c, d). The corresponding storm track (i.e., the bandpass-filtered geopotential height variability in $500 \mathrm{hPa}$ ) has its maximum at $50^{\circ} \mathrm{S}$ and is strongly related to baroclinicity in the lower troposphere and the jet stream maximum (Trenberth 1991). Simmonds et al. (2003) investigated 21 years of the NCEPNCAR2 reanalyses update and show that the high-latitude system density is greatest in the Indian Ocean and to the south of Australia. In general, the numbers in winter exceed those in summer. Unlike the $\mathrm{NH}$, rapidly developing cyclones (so called "bombs") indeed show maximum numbers in winter but are also found in summer. More detailed findings about the $\mathrm{SH}$ storm tracks are found in Hoskins and Hodges (2005).

\subsection{Dependence on observational data sources}

Comparing the number of cyclones in the $\mathrm{NH}$ between NCEP/NCAR and ERA-40 reanalyses for the period from 1978 to 1999, Löptien et al. (2008) found about 10\% (15$20 \%$ ) more cyclones in ERA40 in local winter (summer), along with a good agreement of interannual variability. Hodges et al. (2003) compared four reanalysis datasets of different time duration (ERA15, NCEP-NCAR, NCEPDOE, NASA-DAO) with respect to storm tracks using their feature tracking scheme. In particular, they found a generally good correspondence of the feature tracks for the more intense systems between NCEP and ERA15 reanalysis datasets, even though some details differ: cyclones derived from ERA15 data exhibit systematically stronger intensities in the storm track regions compared to NCEP-reanalysis-results, but intensities around orographic features are weaker. There is also a lack of correspondence between the tracks from the different dataset in terms of weaker systems, particularly in regions known for smallscale activity (e.g., secondary developments and the Mediterranean). In fact, the peculiar cyclone characteristics of the Mediterranean Basin lead to the development of methods specially tuned for this area (e.g., Alpert et al. 1990a, 1990b; Trigo et al. 1999; Picornell et al. 2001; Lionello et al. 2002). Such papers are typical examples of cyclone climatologies computed only for a limited area, and not hemispherically, like most of the references herein.

Focusing on the NP and North American region, Eichler and Higgins (2006) found an excellent agreement of NCEP and ERA40-based cyclone locations and seasonal frequency maxima using the cyclone identification and tracking scheme developed by Serreze et al. (1997). On the other hand, Wang et al. (2006a) argued that the roughly similar total numbers originate from two opposing deviations: ERA40 have a slightly lower number of moderately intense cyclones than the NCEP reanalyses, but a higher number of intense cyclones. A higher number of both intense and weak systems in ERA15 compared to NCEP is confirmed by Hanson et al. 
(2004) for NH winter cyclones. This effect is somewhat larger in the NP storm track region and in the SH than in the NA. Raible et al. (2008), however, state that ERA40 has systematically more cyclones than NCEP (resulting in a higher cyclone track density), and cyclone intensity is also larger in ERA-40. According to their investigation, this result is valid for both the NA and NP basins, and for all seasons. Hanson et al. (2004) compute spatial correlations between ERA15 and NCEP cyclone frequencies as high as $r=0.89$ for intense systems over the NA, but a smaller agreement for weaker ones $(r=0.62)$. The agreement of interannual variability is clearly worse, with a maximum of $r=0.62$ for intense systems. The largest differences between ERA-40 and NCEP, however, are detected in summer, as confirmed by Trigo (2006) and Löptien et al. (2008).

In summary, there is a general agreement of the different reanalysis datasets with respect to cyclone climatologies. Differences in cyclone intensities and in the small-scale and weaker systems in re-analysis (both are higher/more frequent in ERA than in NCEP) can in part be assigned to the influence of spatial resolution of the archived data, which in turn affects identification and tracking methodologies. Trigo (2006) and Benestad and Chen (2006) demonstrated, however, that this does not fully explain the discrepancies between the two reanalysis datasets. Other factors are the dynamics and parameterizations implemented in the numerical forecasting model used in the reanalysis (which is, of course, not independent of spatial resolution). Assimilation of observations into the individual re-analysis schemes will play a role (e.g., Hodges et al. 2003; Trigo 2006), and again spatial resolution will influence a scheme's ability to assimilate extreme cyclones from observations. Note, however, that even in recent highresolution operational analysis the intensity of intense and small-scale systems may not be well represented (see Ulbrich et al. 2001, for the case of the 1999 European storm named "Lothar").

\subsection{Trends and variations in reanalysis data}

While reanalysis products are produced with a fixed model and assimilation scheme, changes in the available observational data (data types, spatial, and temporal densities) can impose some inhomogeneity into these sets, and the IPCC AR4 (cf. Trenberth et al. 2007, p. 312) states that the detection of long-term changes in cyclone measures is hampered by incomplete and changing observing systems. Recent studies found, however, a general reliability of results for cyclones on the NH: There are no sudden shifts in intensities that would indicate inhomogeneities, and also a comparison with cyclone activity estimated from regional surface and radiosonde data (Wang et al. 2006b; Harnik and Chang 2003) confirmed the general reliability of the data, even though there may be some effect of increasing density of observations in some datasets (e.g., in COADS data, see Chang 2005a). In contrast to the NH, several sudden swings occur in the SH, apparently related to changes in the observational data sources available for the reanalysis (Wang et al. 2006a).

\subsubsection{Northern Hemisphere}

Many recent studies show evidence that cyclone frequencies and characteristics have changed in the recent past. Sickmöller et al. (2000) and Gulev et al. (2001) find negative trends in cyclone counts over reanalysis periods (19791997 and 1958-1999, respectively) in both the NA and the NP sectors. McCabe et al. (2001) mention decreases in mid(but not high) latitude cyclone frequencies. Raible et al. (2008) confirms these results for the NA region. The negative trend in cyclone counts over the mid-latitude NA is also found by Wang et al. (2006a), who also state that there is no trend over Northern Europe in the winter. Schneidereit et al. (2007) restrict their study to the Icelandic region, finding an increase in cyclone number over the ERA40 reanalysis period, in agreement with the results by Bartholy et al. (2006) for this area. Increasing cyclone counts over Northern Europe and decreasing numbers over Central Europe over the ERA40 period are confirmed by Trigo (2006). They find similar trends over these regions in NCEP data, while in other regions the result is more dependent on the underlying dataset. Benestad and Chen (2006) find a positive linear trend in the number of intense storms over the Nordic countries over the period 19551994 in both the NCEP and the ERA40 data, but no clear results in the western parts of the NA. With respect to the frequency and intensity of extreme cyclones, Geng and Sugi (2001) and Paciorek et al. (2002) find an increase over both the NA and NP during the second half of the 20th century. According to the study of Gulev et al. (2001), however, there is only a small positive trend for NP deep cyclones (core pressure $<980 \mathrm{hPa}$ ) in NCEP data, and even a negative trend for the Atlantic sector. At the same time, these authors (confirmed by McCabe et al. 2001) compute significant increases in deep cyclone counts over the Arctic. Discrepancies between the statements on trends thus depend on the specific domain boundaries chosen. An overall result is a northward shift of the mid-latitude storm tracks (Wang et al. 2006a; Trigo 2006). Raible et al. (2008) stress that results are also sensitive to both the choice of the tracking scheme and of the reanalysis dataset. In particular, the NCEP data tend to show more significant trends than ERA-40, and the trends over the NP disagree between the methods (see also Wang et al. 2006a).

With respect to mean cyclone intensities, Simmonds and Keay (2002) and Raible et al. (2008) do not find significant 
trends for the NA. Wang et al. (2006a) find an increase of mean winter cyclone intensities (including an enhancement in strength for the intense cyclones) over the NP and the high-latitude NA, corroborating with the increase in counts of intense systems mentioned earlier. Increasing cyclone intensities around Iceland are detected by Schneidereit et al. (2007) in ERA40 data. Geng and Sugi (2001) detect increases in cyclone deepening rate, central pressure gradient and translation speed in the winter NA. Zhang et al. (2004) found an increase in number and intensity of cyclones entering the Arctic from mid-latitudes, but also note a significant low-frequency variability in Arctic cyclone activity (negative in the 1960s and positive in the 1990s). For NP cyclone intensity, Gulev et al. (2001) and Simmonds and Keay (2002) detect a significant positive trend. According to Harnik and Chang (2003), the intensification of the NP storm track is accompanied by a north-eastward shift.

Graham and Diaz (2001) speak of an intensification and eastward extension of deep lows in winter, with $50 \%$ more deep low counts over a period of 50 years. They also find increasing trends in related quantities such as in the maximum zonal wind, maximum wind speed, maximum vorticity in the NP storm track, corroborating the decreasing trend of the minimum central pressure of the identified lows, and increasing eddy variability in the 2-6 day band over the whole NCEP period (1948-1999, factor 1.5 over this period). Note, however, that trends computed separately for different timescales of synoptic variability (see Sect. 2) may not be necessarily consistent with each other (Gulev et al. 2002).

Cyclones are related to large-scale patterns due to the influence of these patterns on their development, and conversely due to the cyclones' statistical and physical effects on the patterns. Wang et al. (2006b) note that Canadian cyclone activity is related to large-scale patterns and phenomena like the NAO, the PDO, and ENSO, and mention a possible predictive skill from these patterns suggested from time-lagged correlations. Variations of the NP storm track with ENSO are mentioned by Eichler and Higgins (2006) and by Orlanski (2005). The Atlantic activity maximum over Newfoundland is also dominantly influenced by the PNA pattern (Notaro et al. 2006), and Walter and Graf (2005) find evidence for a dependence of this relations on the state of the stratospheric polar vortex. With respect to decadal variability, Luksch et al. (2005) identify an ENSO influence on Atlantic cyclones, which are displaced southward (along with reduced counts over Northern Europe) during a positive ENSO regime. Further, baroclinic wave activity over the eastern NA depends on the NAO (e.g., Ulbrich and Christoph 1999; Schneidereit et al. 2007). Mailier et al. (2006) state that the NAO alone is not sufficient for explaining the variability of cyclone counts in the NA region and Western Europe: They identify four additional independent teleconnection patterns as significant factors over Europe: the east Atlantic pattern, the Scandinavian pattern, the east Atlantic-western Russian pattern, and the polar-Eurasian pattern.

The relation of cyclones and large-scale patterns may change with time as pointed out by Gulev et al. (2001). Comparing the periods 1958-1978 and 1979-1999, they find a dominant NAO correlation over the western subtropical NA for the counts of deep (core pressure lower than $980 \mathrm{hPa}$ ) cyclones in the former period, while the PNA correlation is dominant in this region in the latter period. Over the eastern NP, a PNA influence can only be seen in the 1979-1999 period, but not in the former, and correlation of the cyclone counts and the NAO over the Mediterranean Sea is restricted to the latter period. Decadal changes in the pattern positions may in fact be a cause of these changing relationships. Changing NAO patterns were, for example, found in observational data by Hilmer and Jung (2000). Jung et al. (2003) point to a connection between a NAO-related eastward shift in variability and an increase of the number of deep cyclones over the northeastern Atlantic.

Individual cyclones contribute to the variability of quasistationary features like the Aleutian and the Icelandic low. For the Aleutian low, Zhu et al. (2007) show that the changes of cyclone intensity account for $73 \%$ of the relative change of Aleutian low intensity in winter, while cyclone numbers do not change significantly between a strong and a weak Aleutian low. For the Icelandic low, Schneidereit et al. (2007) associate the decreasing mean pressure in the second half of the 20th century with an increasing number and intensity of cyclones in the same area.

\subsubsection{Southern Hemisphere}

Analyzing 40 years of NCEP-NCAR reanalysis data, Fyfe (2003) identifies a significant decrease in the number of cyclones (identified as minima of daily averaged sea level pressure) for a latitude band between $40^{\circ}$ and $60^{\circ} \mathrm{S}$, while over the Antarctic Ocean, a modest increase is found. These findings confirm a study from Simmonds and Keay (2000), who employ a more elaborated scheme based on the Laplacian of SLP (described above). A similar result is achieved by Pezza and Ambrizzi (2003), who diagnose a decline of the total number of winter cyclones and anticyclones in the SH, particular at the end of the 1970s. Special note should be given to the findings concerning only cyclones deeper than $980 \mathrm{hPa}$ : a significant increase is found for the entire SH. In addition, Lim and Simmonds (2002) found a statistically significant increase in the number of explosively deepening (at least $1 \mathrm{hPa}$ per hour) systems. More recently, Wang et al. (2006a) identified an increasing trend of strong-cyclone activity over the circumpolar Southern Ocean in winter (JAS) and summer (JFM) 
analyzing gridded 6-hourly SLP data from ERA40 and NCEP-NCAR reanalysis. A decreasing trend further north $\left(40-60^{\circ} \mathrm{S}\right)$ in winter (JAS) partly corroborate results from Fyfe (2003) and Simmonds and Keay (2000). Pezza and Ambrizzi (2003) point to regional differences in the behavior of cyclones during ENSO warm and cold phases, while finding no significant effect of ENSO on the total hemispheric numbers of cyclones. A similar result is presented in Key and Chan (1999). Pezza et al. (2007) do, however, find a dependence of SH cyclones on the phase of the PDO, with more intense but fewer events during the positive phase of the variability pattern.

Referring to the rather sparse data basis of Reanalysis for the $\mathrm{SH}$, artificial trends due to changes in the observing system are not unlikely. Simmonds and Keay (2000) speculate about "improved" sea ice specifications or changes in the quantity of Antarctic data in order to explain changes in the cyclone behavior just off the Antarctic coast in reanalyses. Thus, it is not clear how far the significant increase in the number of automatic weather stations has influenced reanalyses data as far as they had been included. An improvement with respect to data availability is also the incorporation of buoy and satellite data, especially for the SH and its high latitudes (Simmonds et al. 2003).

\section{GCM results}

\subsection{Recent climate}

One purpose of using automatic schemes is their application to GCM produced datasets. Studies on cyclones in GCMs can help to identify mechanisms influencing cyclone climatologies, for example their sensitivity to variable ocean boundary conditions (e.g., Raible and Blender 2004) or to rising greenhouse gas concentrations. GCMs are particularly well suited for this purpose as the cyclones in a GCM are the sole result of the numerical integration, in contrast to reanalysis which incorporates observational data. The comparison and validation of simulated cyclone activity with reanalysis-derived climatology is an important step in the evaluation of a GCM's reliability. It must be borne in mind that many GCM datasets have a lower spatial and temporal resolution than typical reanalysis products. Pinto et al. (2006), for example, demonstrated that cyclone activity computed from observational data is rather close to that of a model control run (specifically, ECHAM4, T42) when the spatial resolution of the reanalysis dataset (NCEP-NCAR, originally T62) was spectrally reduced to the GCM's standard (cf. also Pinto et al. 2005). Temporal resolution $(6,12$, or $24 \mathrm{~h})$ is also very important, as a lower temporal resolution implies a reduced number of cyclone tracks (e.g., Blender and Schubert 2000;
Zolina and Gulev 2002). Typically, short-lived, weaker cyclones are more affected by a reduction of temporal resolution than large and intense systems. The impacts of the temporal resolution in the results are, however, strongly dependent on the considered parameters. Using the ECMWF model in spectral truncations from T95 to T255, Jung et al. (2006) demonstrate that at these resolutions, the dynamical effect dominates over the truncation effect for intense cyclones, while the truncation effect dominates for shallow cyclones. Note, however, that the relative importance of this effect will depend on the particular identification and tracking method applied.

\subsubsection{Northern Hemisphere}

Ulbrich et al. (2008) recently investigated the ability of 16 coupled atmosphere-ocean GCMs to reproduce the observed storm tracks (standard deviation of synoptic band-pass filtered MSLP variability) under present-day greenhouse gas forcing, confirming their general ability to reproduce the general structure of the storm track pattern with spatial correlations for the hemisphere ranging between $r=0.94$ and $r=0.99$. The representation of statistics based on individual cyclones is more difficult for the GCMs. However, some basic features of climatological cyclone activity are reproduced even at rather low model resolution: Raible et al. (2007) employed an identification and tracking system for their studies using a low-resolution (T31) climate model under present-day greenhouse gas forcing (control simulation), stating that the cyclone climatology produced (their Fig. 2) resembles the observed patterns, while it underestimates cyclone numbers and in particular the maximum in the Mediterranean area. Deficits arising from the low model resolution and (related) lower than observed orography were noted by Bengtsson et al. (2006), who pointed to weaker-than-observed cyclone genesis in the lee of the Rocky Mountains in the ECHAM5 (T63 resolution) model, while the cyclogenesis areas are similar to those in ERA-40. This result is corroborated by Pinto et al. (2006) considering the ECHAM4 GCM, who also identified reduced cyclogenesis in large parts of the Mediterranean Basin (often of lee origin).

GCMs also reproduce basic dependencies on large-scale variability modes: Bengtsson et al. (2006) and Raible and Blender (2004) found that the models they considered feature a realistic response of the NH storm tracks to ENSO variability. An interesting feature is the NP storm track's climatological mid-winter minimum (see Newton 2004; and Robinson et al. 2006 for recent studies), which could also be identified in a GCM (Christoph et al. 1997). Orlanski (2005) performed numerical experiments in order to demonstrate that, besides ENSO, the intrusion of atmospheric waves from the Asian continent is important for the 

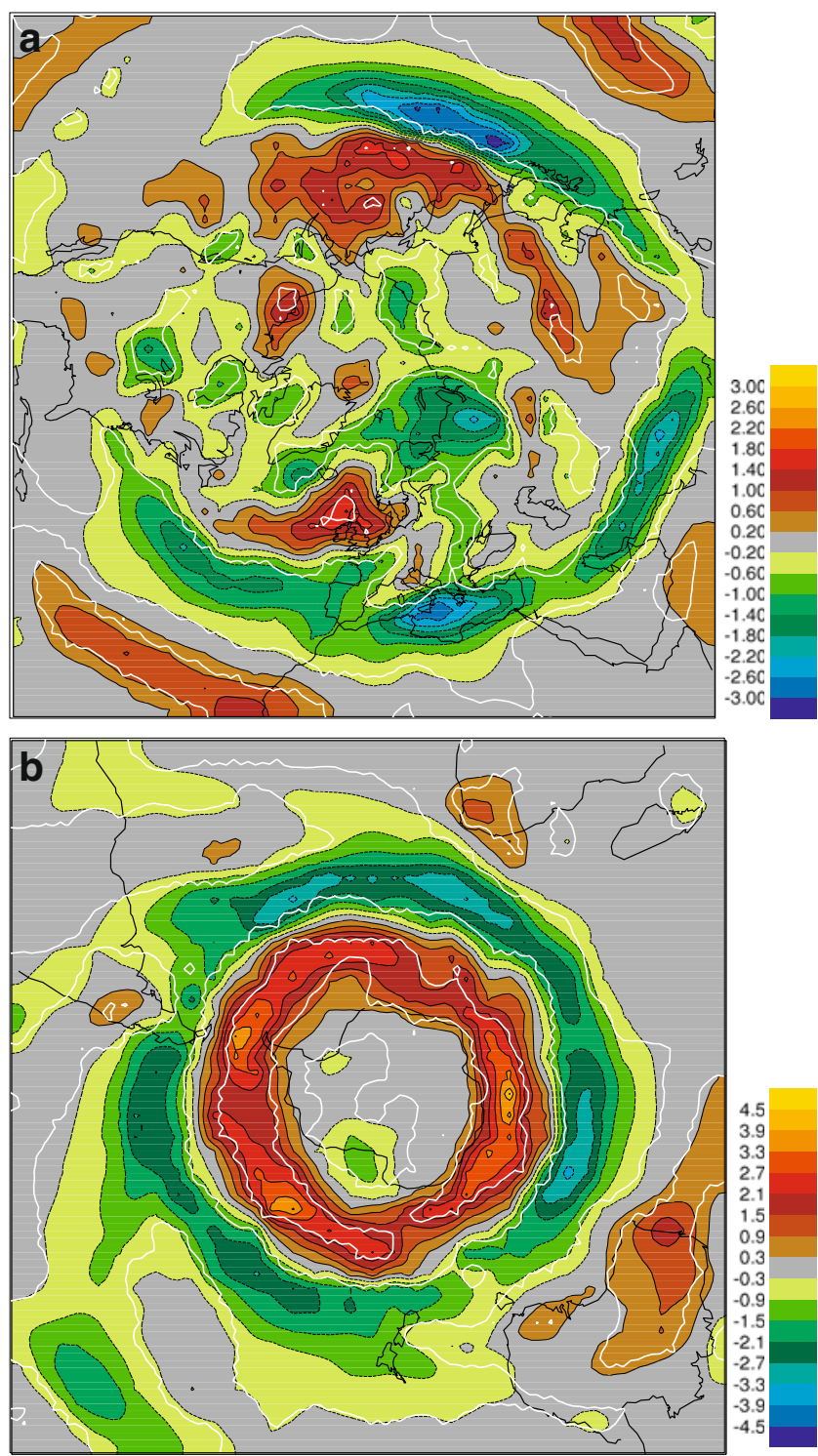

Fig. 2 a ECHAM5-OM1: NH: DJF (winter) difference cyclone track statistics for $\xi_{850}$, between the 2071-2100 and 1961-1990 periods (IPCC A1B scenario) averaged over three ensemble members before differencing. Track-density differences are number density per month per unit area, where the unit area is equivalent to a $5^{\circ}$ spherical cap $\left(\sim 10^{6} \mathrm{~km}^{2}\right)$. The white lines indicate regions where the $p$-values are less than 5\% (figure copied from Bengtsson et al. 2006, their Fig. 10a). b ECHAM5-OM1: SH: JJA (winter) difference cyclone track statistics for $\xi_{850}$, between the 2071-2100 and 1961-1990 periods (IPCC A1B scenario) averaged over three ensemble members before differencing. Track-density differences are number density per month per unit area, where the unit area is equivalent to a $5^{\circ}$ spherical cap $\left(\sim 10^{6} \mathrm{~km}^{2}\right)$. The white lines indicate regions where the $p$-values are less than 5\% (figure copied from Bengtsson et al. 2006, their Fig. 13a)

understanding of NP storm track variability. This is in line with observational evidence (Chang 2005b).

There are several factors that can produce deviations of model climatology from observations. For example, Pinto et al. (2006) associated the fact that cyclone paths in
ECHAM4 are too zonal (particularly over the NA) with corresponding biases in MSLP and upper-air baroclinicity. Similar deviations from observed track climatologies are found in the ECHAM version 5. Pinto et al. (2007c) associated them with deviations in the upper-air jet stream, baroclinicity and with reduced blocking frequencies in comparison to NCEP (cf. Pinto et al. 2007a, their Fig. 7 vs. Pinto et al. 2007c, their Fig. 7). Löptien et al. (2008), however, point out that the ECHAM5/OM1 model is closer to reality than ECHAM4 in many aspects of the representation of cyclones and their life cycles.

Greeves et al. (2007, their Fig. 3b and d), for example, display that the HadGAM1 atmospheric model forced with 1979-1995 SST and sea ice has an Atlantic storm track that does not extend far enough into the European continent, and which is even shorter than the older version's (HadAM3), associated with a tendency to high European pressure (James 2006). Over the Pacific, the model is producing a maximum of cyclone activity (using $500-\mathrm{hPa}$ vorticity tracks) too far west, i.e., close to the dateline rather than in the eastern NP towards the American continent. The authors speculate that this could be related to the model's excessive diabatic heating in the lower troposphere. An ingredient to the model's deviation could also stem from the high values of Eady growth rate, which are larger than suggested by ERA40 over the NP.

Greeves et al. (2007) state that the Hadley Centre's models' representation of cyclone activity depends on the dynamical core and the horizontal resolution: at lower resolution, a semi-Lagrangian core is less able to produce small-scale eddies, which results in weaker eddy kinetic energy and in weaker and fewer cyclonic features. The Eulerian core reacts to reduced resolution with changes in the storm track location, while intensities are less affected. Roeckner et al. (2006) study the effect of increasing resolution of their GCM. They find a poleward (equatorward) shift of the midlatitude westerlies at enhanced horizontal (vertical) resolution which can be assumed to have corresponding effects on cyclones.

\subsubsection{Southern Hemisphere}

A reasonably good representation of present-day cyclone climatologies is also found for the SH. Bengtsson et al. (2006) compare three ECHAM5-OM1 simulations with ERA40 reanalysis data. The general picture of cyclogenesis at midlatitudes with cyclones spiraling towards Antarctica and cyclolysis at its coastlines is well captured by the model, although regional differences exist: in the model, the area of cyclogenesis is more concentrated on the southern part of Patagonia and there is also more cyclogenesis in the Indian Ocean sector and east of Tasmania compared to ERA40. Nevertheless, the authors 
state that the overall performance of ECHAM5-OM1 in the SH is reasonably well. This conclusion confirms earlier findings for 13 models participating in the Atmospheric Model Intercomparison Project (AMIP1, Lambert et al. 2002). This paper states that the general position of the circumpolar trough is situated slightly too far north, although the intensity is generally well simulated.

\subsection{Climate change experiments}

\subsubsection{Northern Hemisphere}

Many recent studies show evidence of a change in cyclone activity under anthropogenic climate change (ACC; e.g., Carnell and Senior 1998; Knippertz et al. 2000; Raible and Blender 2004; Bengtsson et al. 2006; Pinto et al. 2006; Watterson 2006). A major result from an ensemble of different models forced with different greenhouse gas concentrations is that the number of extreme cyclones (core pressure lower than $970 \mathrm{hPa}$ ) increases in winter, whereas the total cyclone number is slightly reduced both in the $\mathrm{NH}$ and the SH (Lambert and Fyfe 2006). According to their simple identification procedure based on MSLP minima, the signal increases towards the end of the 21 st century, which corroborates with the sensitivity of the signal to the scenario chosen. A general decrease of the number of all cyclones on a hemispheric scale is confirmed in other studies (e.g., Bengtsson at al. 2006; Finnis et al. 2007; Pinto et al. 2007c, Löptien et al. 2008; Pinto et al. 2008), as is the increase of signals with intensity of GHG forcing (e.g., Leckebusch and Ulbrich 2004; Pinto et al. 2007c, Lionello et al. 2008). The hemispherically increasing number of extreme events (as suggested by Lambert and Fyfe 2006) is, however, not a general result. Instead, several studies emphasize that enhanced cyclone intensities are only detected for limited areas (e.g., near Great Britain and Aleutian Isles, cf. Bengtsson et al. 2006, their Fig. 10c; Pinto et al. 2007c, their Fig. 3d and Table 2). At the same time, these studies identify an increase (Fig. 2a, originally published in Bengtsson et al. 2006), or no significant changes (Pinto et al. 2007c, their Fig. 3b) of cyclone track density for the same areas. Pinto et al. (2008) considered only developing cyclones (i.e., featuring an intensification phase) and found a decreasing number of extreme cyclones in the $\mathrm{NH}$, but this result is related to the (dominating) reduction of weaker events, as they define "extreme events" as the strongest $10 \%$ of all developing systems. In order to explain the discrepancies concerning the greenhouse gasinduced trends in extreme cyclone counts, we computed these changes in the NH from the ECHAM5/OM1 model runs for present-day climate and the A1B scenario during the last decades of the 21 st century. The result is a decrease in extreme cyclones when "extreme" is defined from the high values (e.g., the 99 percentile for the present-day period) in the Laplacian of pressure, while there is an increase when it is defined in terms of extremely low SLP. In summary, the discrepancy between hemispheric trends in extreme cyclones appears to depend on the question how an "intense event" is defined.

The regional increase of extreme cyclones in the northeast Atlantic adjacent to Central Europe has been detected in both the Hadley Centre and in the ECHAM GCMs (Leckebusch and Ulbrich 2004; Leckebusch et al. 2006), and seems to be largely independent of the quantity considered (Laplacian of pressure, minimum pressure, or cyclone track counts, see Fig. 2a). While a high variability with respect to the exact location and extension of this regional increase is found between models and model runs (Leckebusch et al. 2006), a study of the storm tracks (bandpass-filtered synoptic variability computed from MSLP) in an ensemble of 23 runs out of 16 different coupled GCMs (Ulbrich et al. 2008) confirms a greenhouse gas-induced increase of activity over this area (and over the Aleutian Islands) in spite of considerable differences between the individual models and model runs. Among the 16 GCMs, ECHAM5-OM1 was one of the models closest to the ensemble average, both in terms representation of present climate and of climate change signal. Considering several SRES scenario simulations with the ECHAM5-OM1 GCM, Pinto et al. (2007c) demonstrate an increase in mid-tropospheric storm-track activity over an area reaching from the mid-NA into the Asian continent (cf. their Figs 3a, 4a, c). Regional increases in the northeast Atlantic storm track based on the ECHAM4 model were associated with an eastward movement of the NAO poles by Ulbrich and Christoph (1999). A small eastward shift of the northern NAO pole associated with enhanced intense cyclones over northwestern Europe was also found by Pinto et al. (2008) in an ECHAM5-OM1 model ensemble.

With respect to other cyclone parameters affected by increasing greenhouse gas concentrations, Jiang and Perrie (2007) see an increase of cyclone radius, along with tendencies for a northward shift, but only small increases in intensity and propagation speed. The basis of their results is a mesoscale compressible model (driven by CGCM2 IS92a scenario simulations) for the Northwest Atlantic, evaluating mid-21st century autumns. Löptien et al. (2008) detect a reduced propagation speed along with enhanced deepening rates in the ECHAM5 scenario.

An area that will be apparently particularly affected by climate change is the Mediterranean Basin: many GCM studies (e.g., Carnell and Senior 1998; Lionello et al. 2002; Geng and Sugi 2003; Pinto et al. 2006; Leckebusch et al. 2006; Bengtsson at al. 2006; Pinto et al. 2007c) give evidence of a strong reduction of winter cyclone activity in 
the Mediterranean Basin under ACC, while considering different models, scenarios, and analysis techniques. Löptien et al. (2008) confirm a significant decrease in winter cyclones in this region in the ECHAM5/OM1 model, even though their generation in this region does not decrease. The authors find an increase of Mediterranean cyclones in summer. With respect to intensities, Pinto et al. (2007c) showed evidence that the more intense Mediterranean cyclones may be particularly reduced in a greenhouse gas climate (cf. their Table 2). On the other hand, Lionello et al. (2002) detected more extreme events, though the result was not clearly significant. While Musculus and Jacob (2005) state that in their regional climate model there is an increase of the total number of Mediterranean cyclones, and a decrease of the stronger systems, Gaertner et al. (2007) suggest an increased intensity of extreme cyclones in their ensemble of regional climate models assigned to a development of tropical cyclones in this area. Lionello et al. (2008) see a significant reduction of stormtrack intensity during late summer and autumn over the Mediterranean region, while the number of cyclones increases in summer.

\subsubsection{Southern Hemisphere}

In a recent study, Bengtsson et al. (2006) show results for the austral summer (DJF) and winter (JJA) with a marked poleward shift of the cyclone tracks for all seasons under ACC (Fig. 2b). Three 20-year simulations of the ECHAM5OM1 GCM forced by IPCC SRES A1B scenario were analyzed. The greatest reduction in the number of cyclones occurs around $40^{\circ} \mathrm{S}$ during austral winter over southern Australia and the northern part of New Zealand. An increase in intensity of cyclones in winter is accompanied by a decrease of intensities in summer (DJF) in the same region. On a hemispheric basis, they find a general reduction in the number of weak systems under ACC for both winter and summer, but an increase in the number of stronger systems during winter. Geng and Sugi (2003) investigate two 20-year time slices using a GCM with comparatively high resolution (T106). A decrease in cyclone numbers is found in the $\mathrm{SH}$ midlatitudes which amounts $7 \%$ in local summer (DJF) and $10 \%$ in local winter (JJA) between the control climate and greenhouse gas forcing for the 2050s. The density of strong cyclones increases over the circumpolar regions around Antarctica and over the southeastern coasts of South Africa and South America in both seasons. Geng and Sugi (2003) explain their findings with a decrease of baroclinicity, which is mainly caused by the increase of static stability as an effect of enhanced greenhouse gases.

This is consistent with results from a study concerning the winter cyclone frequencies from 21 model simulations presented by Lambert and Fyfe (2006). This study was carried out for the "committed" climate change, the SRES B1, SRES A1B, and SRES A2 scenarios based on the WCRP CMIP3 multi-model dataset. As well as for the NH for the $\mathrm{SH}$ a decreasing trend for the number of all cyclones is identified under any climate change scenario, whereas an increasing trend in the number of strong cyclones is identified. For the SH, a threshold of $960 \mathrm{hPa}$ was used to separate strong systems. These trends are more pronounced with an enhanced $\mathrm{CO}_{2}$-forcing scenario. These findings corroborate earlier results achieved with the Canadian Climate Centre GCM (Lambert 1995, 2004).

\section{Conclusions}

A large number of studies of cyclone activity have become available in the recent years. This increase in interest of the scientific community is partly due to the availability of basically homogeneous gridded datasets for the observational period, which in conjunction with the numerical schemes for the identification of cyclones and the quantification of their activity allow detailed studies that were not possible in earlier times. In addition, many GCM simulations both for present-day climate and climate scenarios have recently become available. Their evaluation with respect to cyclone activity can in principle serve to give confidence in the simulated effects of increasing greenhouse gas forcing on the mid-latitude climate. All ingredients for in-depth studies and multi-model ensemble simulations are available. Still, the picture arising from the review of work outlined in the previous sections is mixed. Nevertheless, there seems to be an actual consensus on the following findings:

\section{Northern Hemisphere:}

- Two distinct regions of high cyclonic activities can be detected in reanalysis data and in the models, one over the North Pacific and one over the North Atlantic, with a secondary center over the Mediterranean. The representation of the latter center is particularly dependent on the spatial resolution of the data and the model considered.

- Under ACC conditions, the number of all cyclones will be reduced in winter, but in specific regions (over the Northeast Atlantic and British Isles, and in the North Pacific) the number of intense cyclones increases in most models. For the average over the hemisphere, an increase in the number of extreme cyclones is found only when "extreme" is defined in terms of core pressure, while there is a decrease in several models when defining "extreme" from the Laplacian of surface pressure or vorticity around the core. 
Southern Hemisphere:

- A circumpolar band of cyclonic activity exists with maxima over the Southern Indian Ocean and south of the Tasman Sea.

- Under ACC conditions, a southward shift of this band is identified, more or less meridional equally distributed. This will lead to less cyclonic activity around $50^{\circ} \mathrm{S}$ and increased activity around $60^{\circ} \mathrm{S}$

We note that our summary about ACC effects is largely in agreement with a summarizing sentence in the latest IPCC AR4 report stating that "the most consistent results from the majority of the current generation of models show, for a future warmer climate, a poleward shift of storm tracks in both hemispheres that is particularly evident in the SH, with greater storm activity at higher latitudes." (cf. Meehl et al. 2007; p. 789)

It was shown in our review that some results of cyclone related studies seem to disagree even when based on identical data. Part of the reasons for this is the diversity of approaches for cyclone studies, starting from their identification and tracking and ending at the intensity measures. Different thresholds, different physical quantities, and considerations of different atmospheric vertical levels add to a picture which can hardly be combined into a common view of cyclones, their variability, and trends, in the real world and in GCM studies. The conclusion from this situation should not be that investigations of cyclones are restricted to a few "community" approaches. Given that cyclones are very complex three-dimensional features of atmospheric circulation, they include many different physical aspects that cannot be captured by a simple standard approach. A major result is, however, the urgent need for more specific intercomparison studies which demonstrate the differences between the approaches and their results. This may be based, for example, on a few standard cases or periods, and shall enable synthesis of different approaches, resulting in an improved understanding of cyclones.

Acknowledgments This work was partially supported by the European Union Programme Energy, Environment and Sustainable Development under the projects ENSEMBLES (contract GOCE-CT2003-505593-ENSEMBLES) and CIRCE (contract 036961). We would like to thank Markus Donat for preparing Fig. 1, and Sven Ulbrich for computing the changes in extreme cyclones for the $\mathrm{NH}$ in the ECHAM model runs. We are particularly thankful for the very constructive comments and suggestions provided by the three anonymous reviewers, which helped to improve the paper.

Open Access This article is distributed under the terms of the Creative Commons Attribution Noncommercial License which permits any noncommercial use, distribution, and reproduction in any medium, provided the original author(s) and source are credited.

\section{References}

Alpert P, Neeman BU, Shay-El Y (1990a) Climatological analysis of Mediterranean cyclones using ECMWF data. TellusA 42:65-77

Alpert P, Neeman BU, Shay-El Y (1990b) Intermonthly variability of cyclone tracks in the Mediterranean. J Clim 3:1474-1478

Ayrault F, Lalaurette F, Joly A, Loo C (1995) North Atlantic ultra high frequency variability. Tellus 47A:671-696

Bartholy J, Pongrácz R, Pattantyús-Ábrahám M (2006) European cyclone track analysis based on four geopotential fields of ECMWF ERA-40 datasets. Int J Climatol 26:1517-1527

Benestad RE, Chen D (2006) The use of a calculus-based cyclone identification method for generating storm statistics. Tellus 58A:473-486

Bengtsson L, Hodges KI, Roeckner E (2006) Storm tracks and climate change. J Clim 19:3518-3543

Blackmon ML, Wallace JM, Lee Y-H (1984a) Horizontal structure of $500-\mathrm{mb}$ height fluctuations with short, medium and long time scales. J Atmos Sci 41:961-979

Blackmon ML, Wallace JM, Lee Y-H, Hsu H-H (1984b) Time variation of 500-mb height fluctuations with short, medium and long time scales. J Atmos Sci 41:981-991

Blender R, Schubert M (2000) Cyclone tracking in different spatial and temporal resolutions. Mon Wea Rev 128:377-384

Blender R, Fraedrich K, Lunkheit F (1997) Identification of cyclone-track regimes in the North Atlantic. Quart J R Met Soc 123:727-741

Burkhardt U, James IN (2006) The effect of Doppler correction on measures of storm track intensity. Clim Dyn 27:515-530

Carnell RE, Senior CA (1998) Changes in mid-latitude variability due to increasing greenhouse gases and sulphate aerosols. Clim Dyn 14:369-383

Chang EKM (2005a) Effects of secular changes in frequency of observations and observational errors on monthly mean MSLP summary statistics derived from ICOADS. J Clim 18:3623-3633

Chang EKM (2005b) The impact of wave packets propagating across Asia on Pacific cyclone development. Mon Wea Rev 133:1998-2015

Chen SJ, Zhang PZ (1996) Climatology of deep cyclones over Asia and the Northwest Pacific. Theor Appl Climatol 54:139-146

Christoph M, Ulbrich U, Haak U (1995) Faster determination of the intraseasonal variability of stormtracks using Murakami's recursive filter. Mon Wea Rev 123:578-581

Christoph M, Ulbrich U, Speth P (1997) Midwinter suppression of northern hemisphere storm track activity in the real atmosphere and in GCM experiments. J Atmos Sci 54:1589-1599

Deveson ACL, Browning KA, Hewson TD (2002) A classification of FASTEX cyclones using a height-attributable quasi-geostrophic vertical-motion diagnostic. Q J R Meteorol Soc 128:93-117

Eichler T, Higgins W (2006) Climatology and ENSO-related variability of North American extratropical cyclone activity. J Clim 19:2076-2093

Finnis J, Holland MM, Serreze MC, Cassano JJ (2007) Response of northern hemisphere extratropical cyclone activity and associated precipitation to climate change, as represented by the community climate system model. J Geophys Res 112. doi:10.1029/ 2006JG000286

Froude LSR, Bengtsson L, Hodges KI (2007a) The predictability of extratropical storm tracks and the sensitivity of their prediction to the observing system. Mon Wea Rev 135:315-333

Froude LSR, Bengtsson L, Hodges KI (2007b) The prediction of extratropical storm tracks by the ECMWF and NCEP ensemble prediction systems. Mon Wea Rev 135:2545-2567

Fyfe JC (2003) Extratropical southern hemisphere cyclones: harbingers of climate change? J Clim 16:2802-2805

Gaertner MA, Jacob D, Gil V, Domínguez M, Padorno E, Sánchez E, Castro M (2007) Tropical cyclones over the Mediterranean Sea in 
climate change simulations. Geophys Res Lett 34:L14711. doi:10.1029/2007GL029977

Gaffney SJ, Robertson AW, Smyth P, Camargo SJ, Ghil M (2007) Probabilistic clustering of extratropical cyclones using regression mixture models. Clim Dyn 29:423-440

Geng Q, Sugi M (2001) Variability of the North Atlantic cyclone activity in winter analysed from NCEP-NCAR reanalysis data. $\mathrm{J}$ Clim 14:3863-3873

Geng Q, Sugi M (2003) Possible change of extratropical cyclone activity due to enhanced greenhouse gases and sulfate aerosolsstudy with a high-resolution AGCM. J Clim 16:2262-2274

Graham NE, Diaz HF (2001) Evidence for intensification of North Pacific winter cyclones since 1848. Bull Am Met Soc 82:1869-1904

Gray SL, Dacre HF (2006) Classifying dynamical forcing mechanisms using a climatology of extratropical cyclones. Q J R Met Soc 132:1119-1137

Greeves CZ, Pope VD, Stratton RA, Martin GM (2007) Representation of northern hemisphere winter storm tracks in climate models. Clim Dyn 28:683-702

Gulev SK, Zolina O Grigoriev S (2001) Extratropical cyclone variability in the northern hemisphere winter from NCEP/NCAR reanalysis data. Clim Dyn 17:795-809

Gulev SK, Jung T, Ruprecht E (2002) Interannual and seasonal variability in the intensities of synoptic scale processes in the North Atlantic mid latitudes from the NCEP/NCAR reanalysis data. J Clim 15:809-828

Haak U, Ulbrich U (1996) Verification of an objective cyclone climatology for the North Atlantic. Meteorol Z 5:24-30

Hanson CE, Palutikof JP, Davies TD (2004) Objective cyclone climatologies of the North Atlantic - a comparison between the ECMWF and NCEP Reanalyses. Clim Dyn 22:757-769

Harnik N, Chang EKM (2003) Storm track variations as seen in radiosonde observations and reanalysis data. J Clim 16:480 495

Hodges KI (1994) A general method for tracking analysis and its application to meteorological data. Mon Wea Rev 122:2573-2586

Hodges KI (1995) Feature tracking on the unit sphere. Mon Wea Rev 123:3458-3465

Hodges KI, Hoskins BJ, Boyle J, Thorncroft C (2003) A comparison of recent reanalysis datasets using objective feature tracking: storm tracks and tropical easterly waves. Mon Wea Rev 131:2012-2037

Hoskins BJ, Hodges KI (2002) New perspectives on the northern hemisphere winter storm tracks. J Atmos Sci 59:1041-1061

Hoskins BJ, Hodges KI (2005) A new perspective on southern hemisphere storm tracks. J Clim 18:4108-4129

Hilmer M, Jung T (2000) Evidence for a recent change in the link between the North Atlantic Oscillation and Arctic sea ice. Geophys Res Lett 27:989-992

James PM (2006) An assessment of European synoptic variability in Hadley centre global environmental models based on an objective classification of weather regimes. Clim Dyn 27:215-231

Jiang J, Perrie W (2007) The impacts of climate change on autumn North Atlantic midlatitude cyclones. J Clim 20:1174-1187

Jung T, Hilmer M, Ruprecht E, Kleppek S, Gulev SK, Zolina O (2003) Characteristics of the recent eastward shift of interannual NAO variability. J Clim 16:3371-3382

Jung T, Gulev SK, Rudeva I, Soloviov V (2006) Sensitivity of extratropical cyclone characteristics to horizontal resolution in the ECMWF model. Q J R Meteorol Soc 132:1839-1857

Key JR, Chan ACK (1999) Multidecadal global and regional trends in $1,000-\mathrm{mb}$ and $500-\mathrm{mb}$ cyclone frequencies. Geophys Res Lett 26:2053-2056

Knippertz P, Ulbrich U, Speth P (2000) Changing cyclones and surface wind speeds over North Atlantic and Europe in a transient GHG experiment. Clim Res 15:109-122
König W, Sausen R, Sielmann F (1993) Objective identification of cyclones in GCM simulations. J Clim 6:2217-2231

Lambert SJ (1988) A cyclone climatology of the Canadian climate centre general circulation Model. J Clim 1:109-115

Lambert SJ (1995) The effect of enhanced greenhouse warming on winter cyclone frequencies and strengths. J Clim 8:1447-1452

Lambert SJ (2004) Changes in winter cyclone frequencies and strengths in transient enhanced greenhouse warming simulations using two coupled climate models. Atmosphere-Ocean 42:173-181

Lambert SJ, Fyfe JC (2006) Changes in winter cyclone frequencies and strengths simulated in enhanced greenhouse warming experiments: results from the models participating in the IPCC diagnostic exercise. Clim Dyn 26:713-728

Lambert SJ, Sheng J, Boyle J (2002) Winter cyclone frequencies in thirteen models participating in the Atmospheric Model Intercomparison Project (AMIP1). Clim Dyn 19:1-16

Le Treut H, Kalnay E (1990) Comparison of observed and simulated cyclone frequency distribution as determined by an objective method. Atmosphera 3:57-71

Leckebusch GC, Ulbrich U (2004) On the relationship between cyclones and extreme windstorms over Europe under climate change. Glob Planet Change 44:181-193

Leckebusch GC, Koffi B, Ulbrich U, Pinto JG, Spangehl T, Zacharias S (2006) Analysis of frequency and intensity of winter storm events in Europe on synoptic and regional scales from a multimodel perspective. Clim Res 31:59-74

Leckebusch GC, Ulbrich U, Fröhlich EL, Pinto JG (2007) Property loss potentials for European mid-latitude storms in a changing climate. Geophys Res Lett 34:L05703. doi:10.1029/2006GL027663

Leslie LM, Leplastrier M, Buckley BW, Qi L (2005) Climatology of meteorological "bombs" in the New Zealand region. Meteorol Atmos Phys 89:207-214

Lim E-P, Simmonds I (2002) Explosive cyclone development in the southern hemisphere and a comparison with northern hemisphere events. Mon Wea Rev 130:2188-2209

Lim E-P, Simmonds I (2007) Southern hemisphere winter extratropical cyclone characteristics and vertical organization observed with the ERA-40 data in 1979-2001. J Clim 20:2675-2690

Lionello P, Dalan F, Elvini E (2002) Cyclones in the Mediterranean region: the present and the doubled $\mathrm{CO}_{2}$ climate scenarios. Clim Res 22:147-159

Lionello P, Boldrin U, Giorgi F (2008) Future changes in cyclone climatology over Europe as inferred from a regional climate simulation. Clim Dyn 30:657-671

Löptien U, Zolina O, Gulev SK, Latif M, Soloviov V (2008) Cyclone life cycle characteristics over the northern hemisphere in coupled GCMs. Clim Dyn 31:507-532

Luksch U, Raible CC, Blender R, Fraedrich K (2005) Decadal cyclone variability in the North Atlantic. Meteorol Z 14:747-753

Maheras P, Flocas H, Patrikas I, Anagnostopoulou C (2001) A 40year objective climatology of surface cyclones in the Mediterranean region: spatial and temporal distribution. Int $\mathrm{J}$ Climatol 21:109-130

Mailier PJ, Stephenson DB, Ferro CAT, Hodges KI (2006) Serial clustering of extratropical cyclones. Mon Wea Rev 134:2224-2240

Mak M, Deng Y (2007) Diagnostic and dynamical analysis of two outstanding aspects of storm tracks. Dyn Atm Ocean 43:80-99

McCabe GJ, Clark MP, Serreze MC (2001) Trends in northern hemisphere surface cyclone frequency and intensity. J Clim 14:2763-2768

Meehl GA, Stocker TF, Collins WD, Friedlingstein P, Gaye AT, Gregory JM, Kitoh A, Knutti R, Murphy JM, Noda A, Raper SCB, Watterson IG, Weaver AJ, Zhao Z-C (2007) Global climate projections. In: Solomon S, Qin D, Manning M, Chen Z, Marquis M, Averyt KB, Tignor M, Miller HL (eds) Climate change 2007: the physical science basis. Contribution of working group I to the 
fourth assessment report of the intergovernmental panel on climate change. Cambridge University Press, Cambridge

Murray RJ, Simmonds I (1991) A numerical scheme for tracking cyclone centres from digital data. Part I: development and operation of the scheme. Aust Meteorol Mag 39:155-166

Musculus M, Jacob D (2005) Tracking cyclones in regional model data: the future of Mediterranean storms. Adv Geosciences 2:13-19

Newton CW (2004) Associations between twice-yearly oscillations of the North pacific cyclone track and upper-tropospheric circulations over the eastern hemisphere. Mon Wea Rev 132:348-367

Notaro M, Wang WC, Gong W (2006) Model and observational analysis of the northeast US regional climate and its relationship to the PNA and NAO patterns during early winter. Mon Wea Rev 134:3479-3505

Orlanski I (2005) A new look at the Pacific storm track variability: sensitivity to tropical SSTs and upstream seeding. J Atmos Sci 62:1367-1390

Paciorek JC, Risbey JS, Ventura V, Rosen RD (2002) Multiple indices of northern hemisphere cyclonic activity, winters 1949-99. J Clim $15: 1573-1590$

Pezza AB, Ambrizzi T (2003) Variability of southern hemisphere cyclone and anticyclone behaviour: further analysis. J Clim 16:1075-1083

Pezza AB, Simmonds I, Renwick JA (2007) Southern hemisphere cyclones and anticyclones: recent trends and links with decadal variability in the Pacific Ocean. Int J Climatol 27:1403-1419

Picornell MA, Jansà A, Genovés A, Campins J (2001) Automated database of mesocyclones from the Hirlam (INM) $-0,5^{\circ}$ analyses in the Western Mediterranean. Int J Climatol 21:335-354

Pinto JG, Spangehl T, Ulbrich U, Speth P (2005) Sensitivities of a cyclone detection and tracking algorithm: individual tracks and climatology. Meteorol Z 14:823-838

Pinto JG, Spangehl T, Ulbrich U, Speth P (2006) Assessment of winter cyclone activity in a transient ECHAM4-OPYC3 GHG experiment. Meteorol Z 15:279-291

Pinto JG, Brücher T, Fink AH, Krüger A (2007a) Extraordinary snow accumulations over parts of central Europe during the winter of 2005/06 and weather-related hazards. Weather 62:16-21

Pinto JG, Fröhlich EL, Leckebusch GC, Ulbrich U (2007b) Changes in storm loss potentials over Europe under modified climate conditions in an ensemble of simulations of ECHAM5/MPIOM1. Nat Hazards Earth Syst Sci 7:165-175

Pinto JG, Ulbrich U, Leckebusch GC, Spangehl T, Reyers M, Zacharias S (2007c) Changes in storm track and cyclone activity in three SRES ensemble experiments with the ECHAM5/MPIOM1 GCM. Clim Dyn 29:195-210

Pinto JG, Zacharias S, Fink AH, Leckebusch GC, Ulbrich U (2008) Environmental factors contributing to the development of extreme cyclones and their relationship with NAO. Clim Dyn, published online. doi:10.1007/s00382-008-0396-4

Raible CC (2007) On the relation between extremes of midlatitude cyclones and the atmospheric circulation using ERA40. Geophys Res Lett 34:L07703. doi:10.1029/2006GL029084

Raible CC, Blender R (2004) North hemisphere midlatitude cyclone variability in GCM-simulations in different ocean representations. Clim Dyn 22:239-248

Raible CC, Yoshimori M, Stocker TF, Casty C (2007) Extreme midlatitude cyclones and their implications to precipitation and wind speed extremes in simulations of the maunder minimum versus present day conditions. Clim Dyn 28:409-423

Raible CC, Della-Marta P, Schwierz C, Wernli H, Blender R (2008) Northern hemisphere extratropical cyclones: a comparison of detection and tracking methods and different reanalyses. Mon Wea Rev 136:880-897

Rice J (1982) The Derivation of Computer-based Synoptic Climatology of Southern Hemisphere Extratropical Cyclones. Honours Thesis. Department of Meteorology. University of Melbourne
Robinson DP, Black RX, McDaniel BA (2006) A Siberian precursor to midwinter intraseasonal variability in the North Pacific storm track. Geophys Res Lett 33:L15811. doi:10.1029/2006GL026458

Roeckner E, Brokopf R, Esch M, Giorgetta M, Hagemann S, Kornblueh L, Manzini E, Schlese U, Schulzweida U (2006) Sensitivity of simulated climate to horizontal and vertical resolution in the ECHAM5 atmosphere model. J Clim 19:3771-3791

Rudeva I, Gulev SK (2007) Climatology of cyclone size characteristics and their changes during the cyclone life cycle. Mon Wea Rev 135:2568-2587

Schinke H (1993) On the occurrence of deep cyclones over Europe and the North Atlantic in the period 1930-1991. Contrib Atmos Phys 66:223-237

Schneidereit A, Blender R, Fraedrich K, Lunkheit F (2007) Iceland climate and North Atlantic cyclones in ERA40 reanalyses. Meteorol Z 16:17-23

Serreze MC (1995) Climatological aspects of cyclone development and decay in the Arctic. Atmos-Ocean 33:1-23

Serreze MC, Carse F, Barry RG, Rogers JC (1997) Icelandic Low cyclone activity: climatological features, linkages with the NAO and relationships with recent changes elsewhere in the Northern Hemisphere circulation. J Clim 10:453-464

Sickmöller M, Blender R, Fraedrich K (2000) Observed winter cyclone tracks in the northern hemisphere in re-analysed ECMWF data. Q J R Meteorol Soc 126:591-620

Simmonds I (2000) Size changes over the life of sea level cyclones in the NCEP reanalysis. Mon Wea Rev 128:4118-4125

Simmonds I, Keay K (2000) Variability of Southern Hemisphere Extratropical Cyclone Behaviour, 1958-97. J Clim 13:550-561

Simmonds I, Keay K (2002) Surface fluxes of momentum and mechanical energy over the North Pacific and North Atlantic Oceans. Meteorol Atmos Phys 80:1-18

Simmonds I, Murray RJ, Leighton RM (1999) A refinement of cyclone tracking methods with data from FROST. Aust Met Mag - Spec Ed:35-49

Simmonds I, Keay K, Lim EP (2003) Synoptic activity in the seas around Antarctica. Mon Wea Rev 131:272-288

Sinclair MR (1994) An objective cyclone climatology for the southern hemisphere. Mon Wea Rev 122:2239-2256

Sinclair MR (1995) A climatology of cyclogenesis for the southern hemisphere. Mon Wea Rev 123:1601-1619

Sinclair MR (1997) Objective identification of cyclones and their circulation intensity, and climatology. Weather Forecasting 12:595-612

Trenberth KE (1991) Storm tracks in the southern hemisphere. J Atmos Sci 48:2159-2178

Trenberth KE, Jones PD, Ambenje P, Bojariu R, Easterling D, Klein Tank A, Parker D, Rahimzadeh F, Renwick JA, Rusticucci M, Soden B, Zhai P (2007) Global climate projections. In: Solomon S, Qin D, Manning M, Chen Z, Marquis M, Averyt KB, Tignor M, Miller HL (eds) Climate change 2007: the physical science basis. Contribution of working group I to the fourth assessment report of the intergovernmental panel on climate change. Cambridge University Press, Cambridge

Trigo IF (2006) Climatology and interannual variability of stormtracks in the Euro-Atlantic sector: a comparison between ERA-40 and NCEP/NCAR reanalyses. Clim Dyn 26:127-143

Trigo IF, Davies TD, Bigg GR (1999) Objective climatology of cyclones in the Mediterranean region. J Clim 12:1685-1696

Ulbrich U, Christoph M (1999) A shift of the NAO and increasing storm track activity over Europe due to anthropogenic greenhouse gas forcing. Clim Dyn 15:551-559

Ulbrich U, Fink AH, Klawa M, Pinto JG (2001) Three extreme storms over Europe in December 1999. Weather 56:70-80

Ulbrich U, Brücher T, Fink AH, Leckebusch GC, Krüger A, Pinto JG (2003) The central European floods in August 2002. Part II: 
synoptic causes and considerations with respect to climate change. Weather 58:434-442

Ulbrich U, Pinto JG Kupfer H, Leckebusch GC, Spangehl T, Reyers M (2008) Northern Hemisphere storm tracks in an ensemble of IPCC climate change simulations. J Clim 21:1669-1679

Van Bebber WJ (1891) Die Zugstraßen der barometrischen Minima nach den Bahnenkarten der Deutsche Seewarte für den Zeitraum 1875-1890. Meteorol Z 8:361-366

Wallace JM, Gutzler DS (1981) Teleconnections in the geopotential height field during the Northern Hemisphere winter. Mon Wea Rev 109:784-812

Wallace JM, Lim G, Blackmon ML (1988) Relationship between cyclone tracks, anticyclone tracks and barocline wave guides. $\mathrm{J}$ Atmos Sci 45:439-462

Walter K, Graf H-F (2005) The North Atlantic variability structure, storm tracks, and precipitation depending on the polar vortex strength. Atmos Chem Phys 5:239-248

Wang XLL, Swail VR, Zwiers FW (2006a) Climatology and changes of extratropical cyclone activity: comparison of
ERA40 with NCEP-NCAR reanalysis for 1958-2001. J Clim 19:3145-3166

Wang XLL, Swail VR, Zwiers FW (2006b) Observed changes in cyclone activity in Canada and their relationships to major circulation regimes. J Clim 19:895-906

Watterson IG (2006) The intensity of precipitation during extratropical cyclones in global warming simulations: a link to cyclone intensity? Tellus 58A:82-97

Wernli H, Schwierz C (2006) Surface cyclones in the ERA-40 dataset, part I, novel identification method and flobal climatology. J Atmos Sci 63:2486-2507

Zhang XD, Walsh JE, Zhang J, Bhatt US, Ikeda M (2004) Climatology and interannual variability of arctic cyclone activity 1948-2002. J Clim 17:2300-2317

Zhu XJ, Sun JLK, Liu ZY, Liu QY, Martin HE (2007) A synoptic analysis of the interannual variability of winter cyclone activity in the Aleutian low region. J Clim 20:1523-1538

Zolina O, Gulev SK (2002) Improving the accuracy of mapping cyclone numbers and frequencies. Mon Wea Rev 130:748-759 